\title{
Machinable Cu-40\%Zn Composites Containing Graphite Particles by Powder Metallurgy Process
}

\author{
Katsuyoshi Kondoh, ${ }^{1}$ Hisashi Imai, ${ }^{1}$ Yoshiharu Kosaka, ${ }^{2}$ Akimichi Kojima, ${ }^{2}$ \\ and Junko Umeda ${ }^{1}$ \\ ${ }^{1}$ Joining and Welding Research Institute, Osaka University, 11-1 Mihogaoka, Ibaragi, Osaka 567-0047, Japan \\ ${ }^{2}$ Development and engineering division, SAN-ETSU METAL Co. Ltd, 1892 Ota, Tonami, \\ Toyama 939-1315, Japan
}

Correspondence should be addressed to Katsuyoshi Kondoh, kondoh@jwri.osaka-u.ac.jp

Received 29 December 2008; Accepted 11 March 2009

Recommended by Ludo Froyen

Advanced $\mathrm{Cu}-40$ mass $\% \mathrm{Zn}$ alloys with a high tensile strength and excellent machinability have been developed via a powder metallurgy $(\mathrm{P} / \mathrm{M})$ process. They are environmentally benign because fine graphite particles are included instead of lead $(\mathrm{Pb})$ to improve their machinability. The effect of the content and particle size of the graphite on the mechanical properties and machinability are investigated in this paper. When applying a conventional $\mathrm{P} / \mathrm{M}$ process consisting of the cold compaction and hot extrusion to consolidate elementally premixed mixture of $\mathrm{Cu}-40$ mass $\% \mathrm{Zn}$ and graphite powder, the addition of 1 mass $\%$ graphite particles with $5 \sim 10 \mu \mathrm{m}$ in diameter is suitable to obtain a high tensile strength and good machinability at the same time.

Copyright ( $\odot 2009$ Katsuyoshi Kondoh et al. This is an open access article distributed under the Creative Commons Attribution License, which permits unrestricted use, distribution, and reproduction in any medium, provided the original work is properly cited.

\section{Introduction}

$\mathrm{Cu}-40 \mathrm{mass} \% \mathrm{Zn}$ (brass) alloys have a good balance of strength and ductility at room temperature, nonmagnetic properties, and excellent malleability and machinability, which are strongly required in fabricating industrial components. They also show a superior corrosion resistance inneutral and acidified $\mathrm{NaCl}$ solution [1]. It is well known that lead $(\mathrm{Pb})$ is one of the hazardous materials and should be reduced in the use of products. It is, however, necessary to add $1 \sim 4$ mass $\%$ of $\mathrm{Pb}$ for the improvement of the machinability of $\mathrm{Cu}-40$ mass\% $\mathrm{Zn}$ alloys used for the water supply parts and electrical products. From a viewpoint of the environmentally benign issues, $\mathrm{Pb}$-free brass alloys with a good machinability should be developed. It is also well known that graphite particles are environmentally benign and not expensive materials. The addition of them to the metals can reduce and stabilize the friction coefficient under dry sliding condition. Previous works reported the use of the graphite particles instead of $\mathrm{Pb}$ as the additives into brass alloys were investigated in the conventional casting process [2-5]. It was difficult to uniformly disperse them in the matrix of a cast brass billet because the large difference of the specific gravity between the graphite and brass alloy causes the floatation of the graphite particles in the molten brass alloy and their segregation in the cast billet [5]. In this study, $\mathrm{P} / \mathrm{M}$ process is employed to prepare brass alloys uniformly dispersed graphite particles because there is a very limited effect of the large difference of the specific gravity on the segregation of the graphite particles in the elemental mixture powder. The effect of the particle size and content of the added graphite particles on the mechanical properties and machinability of $\mathrm{P} / \mathrm{M}$ extruded $\mathrm{Cu}-40$ mass\%Zn-graphite composites is investigated.

\section{Experimental Procedures}

Water-atomized $\mathrm{Cu}-40$ mass\%Zn alloy powders without $\mathrm{Pb}$, $\mathrm{Bi}$, and $\mathrm{Cd}$, having a mean particle size of $245 \mu \mathrm{m}$, were 


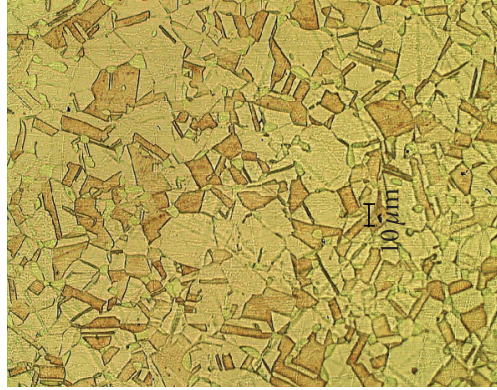

(a) Cast billet

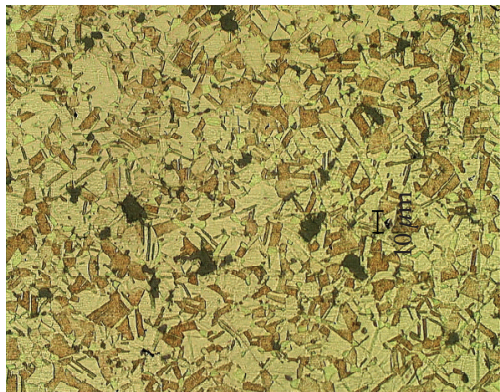

(d) $\mathrm{P} / \mathrm{M}(15 \mu \mathrm{m}-\mathrm{Gr} ; 0.8 \%)$

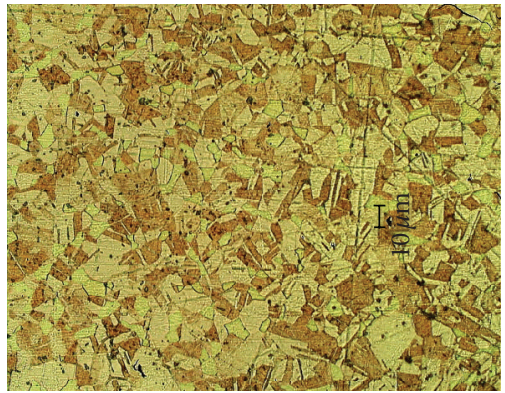

(b) $\mathrm{P} / \mathrm{M}$ billet (Gr; $0 \%)$



(e) $\mathrm{P} / \mathrm{M}(15 \mu \mathrm{m}-\mathrm{Gr} ; 1.0 \%)$

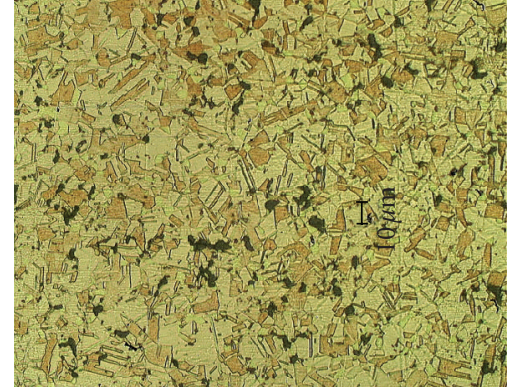

(c) $\mathrm{P} / \mathrm{M}(5 \mu \mathrm{m}-\mathrm{Gr} ; 1.0 \%)$

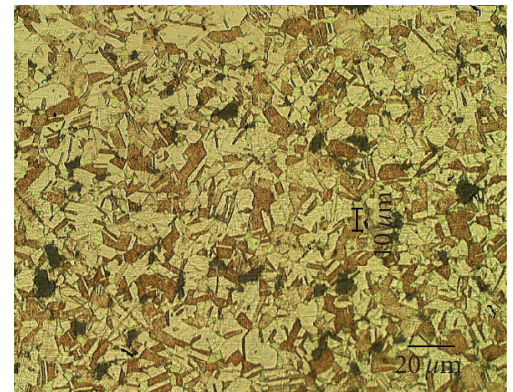

(f) $\mathrm{P} / \mathrm{M}(15 \mu \mathrm{m}-\mathrm{Gr} ; 1.2 \%)$

Figure 1: Optical microstructures of hot extruded $\mathrm{Cu}-40 \% \mathrm{Zn}$ alloys by using cast billet (a) and P/M billets with various contents of graphite particles (b)-(f). (unit; mass\%).

used as the raw materials. It was useful to prepare metallic powder with refined microstructures, which would improve the mechanical property [6]. Graphite powders with a mean particle size of $5 \mu \mathrm{m}, 15 \mu \mathrm{m}$, and $50 \mu \mathrm{m}$ were employed as the additives. The maximum content of graphite particles in the elemental mixture of brass and graphite powder was 1.2 mass\%. After ball-milling the mixture for $3.6 \mathrm{ks}$, each one was compacted at room temperature by the $2000 \mathrm{kN}$ hydraulic press machine. The green compact was heated at $1033 \mathrm{~K}$ for $2.4 \mathrm{ks}$ in nitrogen gas atmosphere and immediately hot extruded as rod materials with $10 \mathrm{~mm}$ in diameter. The short heating time of $2.4 \mathrm{ks}$ is applied in hot extrusion because $\mathrm{Zn}$ vaporization easily occurs during heating, and the composition at the surface of the green compact changes. Optical microstructure observation and tensile tests of each extruded brass alloy were carried out. Concerning the machinability evaluation, the comparison of the machining time to drill a $4.5 \mathrm{~mm}$ diameter hole with $5 \mathrm{~mm}$ depth in each material by applying $9.8 \mathrm{~N}$ load was evaluated. After 10 drilling tests, the mean machining time is used as a machinability parameter of each brass alloy in this study.

\section{Results and Discussion}

Figure 1 shows optical microstructure of $\mathrm{P} / \mathrm{M}$ extruded brass alloys with various contents of graphite particles, compared with the extruded $\mathrm{Cu}-40$ mass $\% \mathrm{Zn}$ cast alloy. Even when containing 1.2 mass\% of graphite particles, they are uniformly dispersed in the matrix, and no segregation of them is observed. The mean grain size of $\mathrm{P} / \mathrm{M}$ materials is $8 \sim 10 \mu \mathrm{m}$, which is finer than that of the extruded brass cast alloy with a mean grain size of $18 \mu \mathrm{m}$. This is because the refined microstructures by the rapid solidification during the atomization are maintained in the extruded materials. Figure 2 indicates a dependence of the tensile test results on the content of the graphite particles. In the case of 0 mass\% graphite content, $\mathrm{P} / \mathrm{M}$ brass alloy shows a superior tensile strength to extruded brass cast alloy due to its fine grains as mentioned in Figure 1. There is no remarkable decrease of tensile strength when adding 1.2 mass $\%$ graphite. However, its elongation gradually decreases with increasing the graphite content because a poor ductility of graphite particulates causes the decrease of the elongation of the composite. Figure 3 shows a fractured surface of the tensile test specimen containing 0.5 mass $\%$ graphite particles with $5 \mu \mathrm{m}$. Small and uniform dimple patterns are observed at the brass matrix. It means a good bonding between the primary brass alloy powders by hot extrusion and results in high tensile strength. However, a poor bonding between the graphite particle and primary brass powder also causes the decrease of the ductility of the P/M materials. Figure 4 shows a dependence of the machining time in the machinability test by drilling holes on the graphite particle content of $\mathrm{P} / \mathrm{M}$ brass alloys. The performance of the conventional brass alloy containing $\mathrm{Pb}$ is shown as a broken 



$\checkmark$ Cast billet
$\square \mathrm{P} / \mathrm{M}(50 \mu \mathrm{m}-\mathrm{Gr})$
- $\mathrm{P} / \mathrm{M}(\mathrm{Gr} ; 0 \%)$
$\Delta \mathrm{P} / \mathrm{M}(5 \mu \mathrm{m}-\mathrm{Gr})$

O $\mathrm{P} / \mathrm{M}(15 \mu \mathrm{m}-\mathrm{Gr})$

(a)

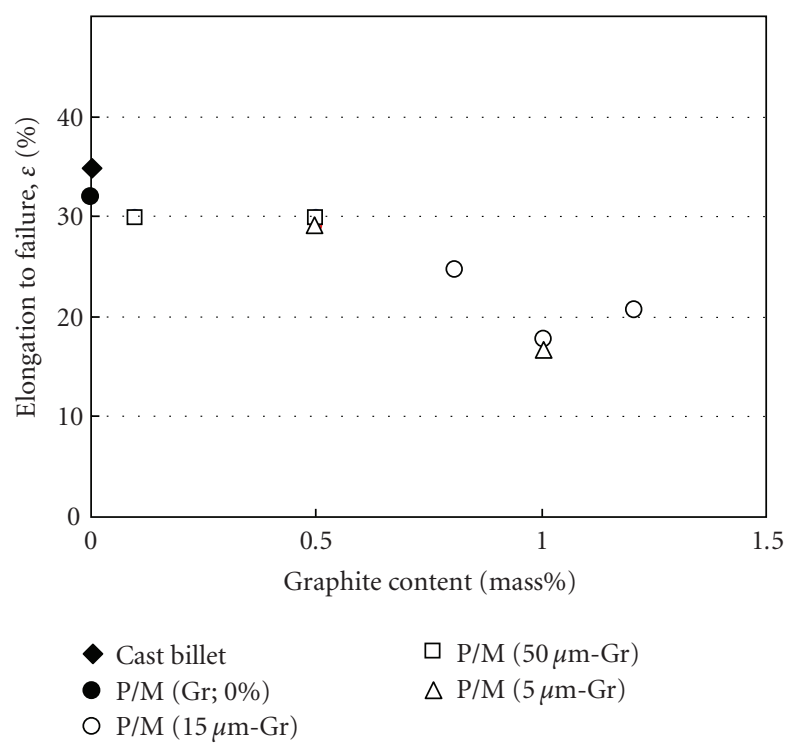

(b)

FIGURE 2: Tensile property dependence on graphite particle content of P/M extruded $\mathrm{Cu}-40 \% \mathrm{Zn}$ alloys; (a) tensile strength and (b) elongation to failure.

line. In the case of 0.1 mass $\%$ graphite, it was impossible to drill a hole in the specimen demonstrating a very poor machinability. The machining time proportionally decreases with increase in the graphite content. When containing 1.2 mass $\%$ graphite particles, the machining time is almost same as that of the brass with $\mathrm{Pb}$ alloy. Accordingly, the addition of graphite particles is effective to improve the machinability of $\mathrm{P} / \mathrm{M}$ brass alloys. However, their elongation is smaller than that of a conventional brass alloy containing $\mathrm{Pb}$.

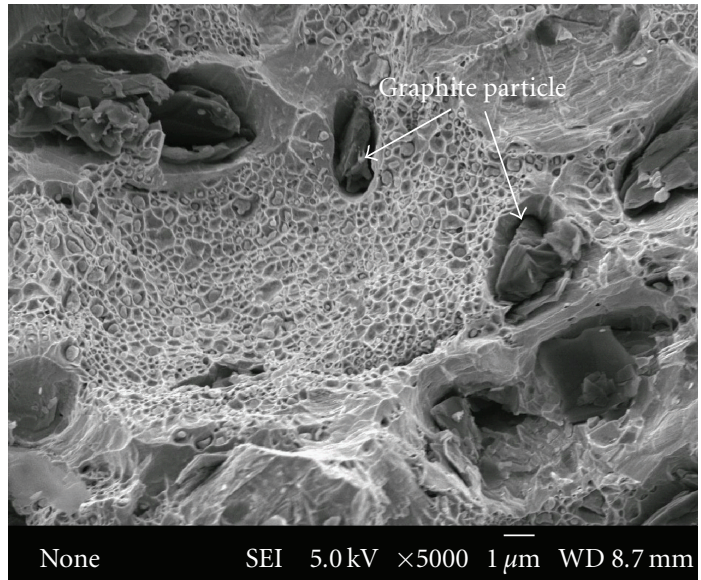

FIGURE 3: SEM observation on fractured surface of tensile test specimen of $\mathrm{P} / \mathrm{M}$ extrude brass alloy with 0.5 mass $\%$ graphite size of $5 \mu \mathrm{m}$ in diameter.

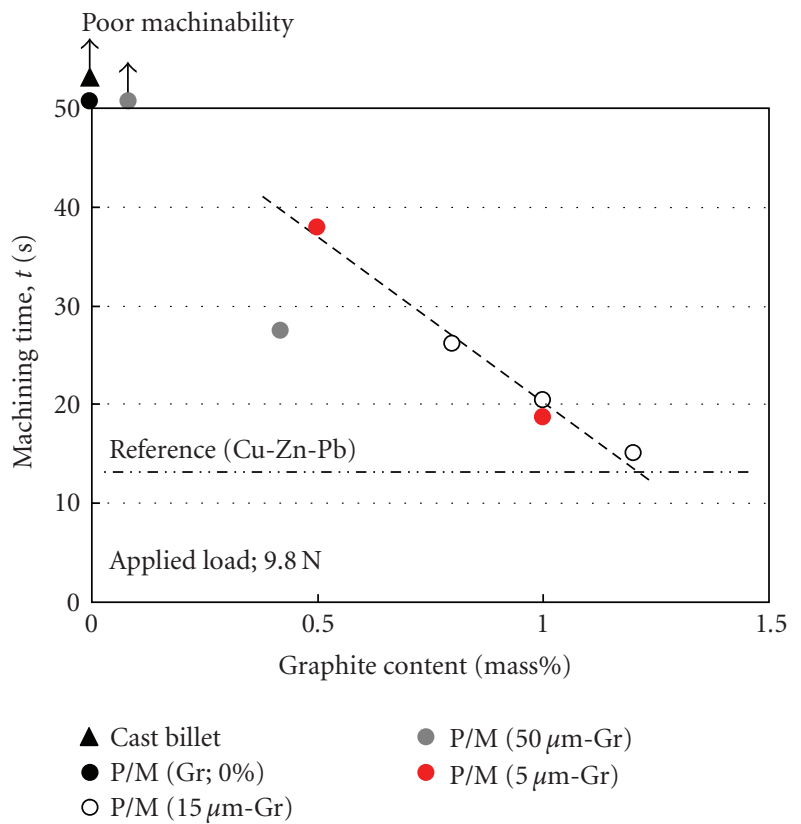

FIGURE 4: Dependence of the machining time in drilling hole test on graphite particle content of $\mathrm{P} / \mathrm{M}$ brass alloys, compared with $\mathrm{Cu}-$ $40 \mathrm{mass} \% \mathrm{Zn}-3 \mathrm{mass} \% \mathrm{~Pb}$ alloy.

\section{Conclusion}

A powder metallurgy process is available to prepare extruded $\mathrm{Cu}-40 \mathrm{mass} \% \mathrm{Zn}$ brass alloys uniformly dispersed fine graphite particles. The increase of the graphite particle content causes the decrease of a ductility of the wrought alloy while the tensile strength is higher than the conventional brass alloy prepared via ingot metallurgy process. The machinability strongly depends on the graphite content, and about 1 mass $\%$ content is enough to serve the same machinability to $\mathrm{P} / \mathrm{M}$ brass alloy as the conventional brass alloy containing lead. 


\section{References}

[1] S. Kumar, T. S. N. S. Narayanan, A. Manimaran, and M. S. Kumar, "Effect of lead content on the dezincification behaviour of leaded brass in neutral and acidified 3.5\% $\mathrm{NaCl}$ solution," Materials Chemistry and Physics, vol. 106, no. 1, pp. 134-141, 2007.

[2] P. K. Rohatgi, S. Ray, D. Nath, and N. Church, "Lead-free machinable copper alloy castings containing graphite," AFS Transactions, vol. 100, pp. 1-9, 1992.

[3] A. Saigal and P. K. Rohatgi, "Machinability of cast lead-free yellow brass containing graphite particles," AFS Transactions, vol. 104, pp. 225-228, 1996.

[4] P. K. Rohatgi, J. Kim, J. Sobczak, and N. Sobczak, "Casting of copper alloys containing dispersed graphite particles in rotating moulds," Foundryman, vol. 91, no. 5, pp. 167-170, 1998.

[5] T. Kobayashi, T. Maruyama, K. Nakao, and Y. Murakami, "Structure and machinability on hot extrusion material of $\mathrm{Pb}$ free $\mathrm{Cu}-\mathrm{Zn}$ system alloy which dispersed fine graphite particles," Journal of Japan Research Institute for Advanced Copper-Base Materials and Technologies, vol. 42, pp. 223-228, 2003.

[6] O. D. Neikov, Yu. V. Milman, A. I. Sirko, A. V. Sameljuk, and A. V. Krajnikov, "Elevated temperature aluminum alloys produced by water atomization," Materials Science and Engineering A, vol. 477, no. 1-2, pp. 80-85, 2008. 

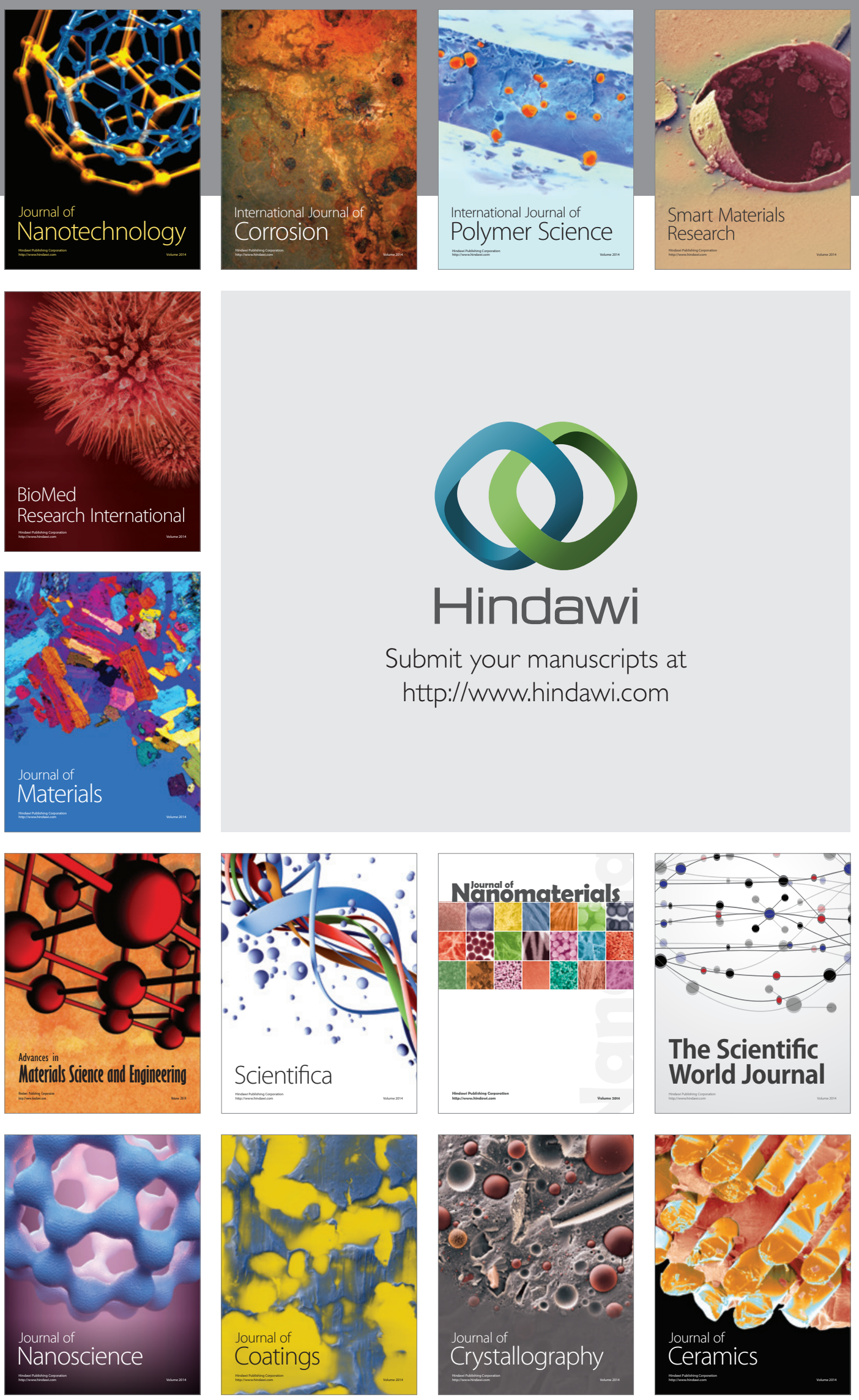

The Scientific World Journal

Submit your manuscripts at

http://www.hindawi.com

\section{World Journal}

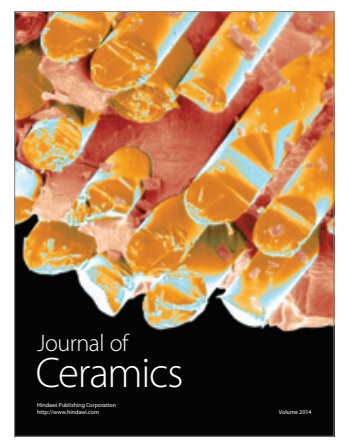


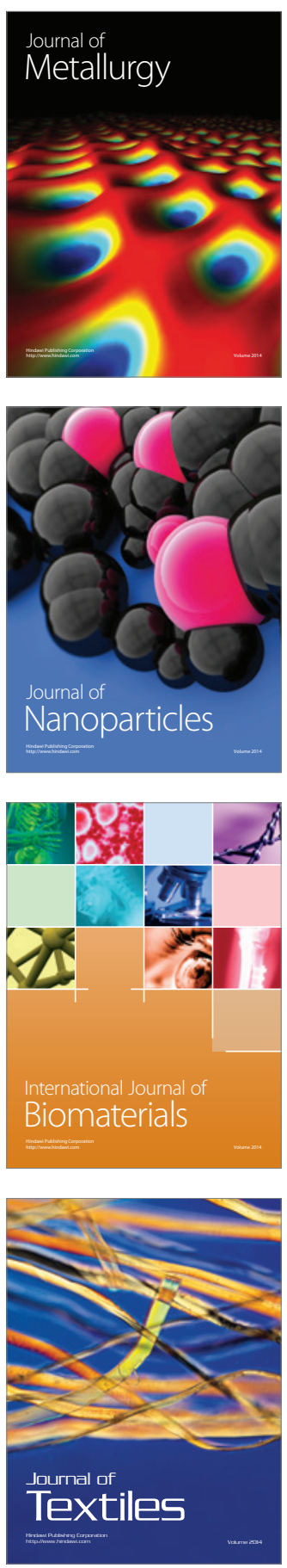